\title{
Obesity and the diagnostic accuracy for primary aldosteronism
}

\author{
Amit Tirosh MD ${ }^{1,2}$ (D) | Fady Hannah-Shmouni MD ${ }^{1}$ | Charalampos Lyssikatos \\ MD $^{1}$ | Elena Belyavskaya MD ${ }^{1}$ | Mihail Zilbermint MD $^{3,4}$ | Smita B. Abraham \\ MD $^{1}$ | Maya B. Lodish MD ${ }^{1}$ Constantine A. Stratakis MD, DMSci ${ }^{1}$
}

${ }^{1}$ Section on Endocrinology and Genetics, Eunice Kennedy Shriver National Institute of Child Health and Human Development, National Institutes of Health, Bethesda, MD, USA

${ }^{2}$ Sackler Faculty of Medicine, Tel Aviv University, Tel Aviv, Israel

${ }^{3}$ Division of Endocrinology, Diabetes, and Metabolism, Johns Hopkins University School of Medicine, Baltimore, MD, USA

${ }^{4}$ Suburban Hospital, Bethesda, MD, USA

\section{Correspondence}

Amit Tirosh, MD, The Eunice Kennedy Shriver National Institute of Child Health and Human Development, National Institutes of Health, Bethesda, MD, USA.

Email: amit.tirosh@nih.gov

\section{Funding information}

This research was supported in part by the Intramural Research Program of Eunice Kennedy Shriver National Institute of Child Health and Human Development, National Institutes of Health.
The effects of body mass index on the diagnostic accuracy of primary aldosteronism (PA) are inconsistent and yet important considering the high prevalence and frequent co-occurrence of obesity and hypertension. The current study included 59 adult patients who underwent a stepwise evaluation for PA, using aldosterone to renin ratio for case detection and plasma aldosterone concentration after saline suppression test and/or 24-hour urinary aldosterone after oral sodium loading for case confirmation. Body mass index had a quadratic (U-shaped) correlation with plasma aldosterone concentration, plasma renin activity, aldosterone to renin ratio, and plasma aldosterone concentration after saline suppression test. Among patients with a body mass index $\geq 30 \mathrm{~kg} / \mathrm{m}^{2}$, the aldosterone to renin ratio yielded lower case detection accuracy of PA. We conclude that obesity results in a nonlinear correlation with plasma aldosterone concentration, plasma renin activity, and aldosterone to renin ratio, which affects the accuracy of case detection for PA. Patients with a body mass index $\geq 30 \mathrm{~kg} / \mathrm{m}^{2}$ are less accurately identified as having PA when saline suppression and/or oral salt loading tests are used for case confirmation.

\section{1 | INTRODUCTION}

Primary aldosteronism (PA) is the leading cause of endocrine hypertension and encompasses a group of diseases in which aldosterone is autonomously secreted from the adrenal glands. ${ }^{1}$ The most common cause of PA is bilateral adrenocortical hyperplasia, followed by aldosteroneproducing adenomas. Current studies estimate that PA is the underlying etiology in approximately $10 \%$ of patients with hypertension. ${ }^{2}$ Identifying patients with PA is clinically important given their increased cardiovascular risk and the potential for surgical and other treatment. ${ }^{3}$

The high prevalence of PA and its deleterious effects ${ }^{3}$ on the cardiovascular system requires a diagnostic algorithm that enables accurate case detection. The 2016 Endocrine Society Guidelines ${ }^{1}$ recognize PA as a major public health issue given its high prevalence, and suggests screening approximately $50 \%$ of hypertensive patients. ${ }^{4}$ An established case detection test for PA is the plasma

Clinical Trial Registration Number: NCT00005927 aldosterone concentration (PAC) to plasma renin activity (PRA) ratio (ARR). Significant variability in cutoff values exist mainly because of a lack of uniformity in diagnostic protocols, cohort selection, assay methods, disease definition, and individual factors, including medication use, age, sex, and presence of renal disease. ${ }^{1}$ Suppression tests using either saline infusion (SST), oral sodium loading, fludrocortisone, or captopril challenge tests are used for case confirmation with varying sensitivity and specificity.

In the United States, $34.9 \%$ of adults are obese. ${ }^{5}$ Although increased aldosterone levels are one of the suggested drivers for obesity-related hypertension, ${ }^{6}$ the exact mechanisms remain elusive. ${ }^{7}$ Previous studies have shown that body mass index (BMI) correlates with PAC and urinary aldosterone (UA) excretion in normotensive healthy persons and women, ${ }^{8}$ and an increased ARR has been described in obese hypertensive women. ${ }^{9}$ However, the impact of BMI on PAC, ARR, and the accuracy of PA case detection has yielded inconsistent results. ${ }^{8,10-13}$ Thus, we sought to determine the impact of obesity on the case detection of PA, which has important implications 
for the interpretation of ARR in the evaluation of individuals with hypertension.

\section{2 | PATIENTS AND METHODS}

\section{1 | Clinical protocol}

A prospective analysis from 2002 to 2015 of 59 patients with PA was performed. Patients were referred for clinical evaluation based on the following categories: adrenocortical incidentaloma or bilateral adrenocortical hyperplasia (49.2\%), hypokalemic hypertension (32.2\%), and resistant hypertension (18.6\%, Figure 1). Patients with suspected Cushing syndrome or co-secretors (secretion of both aldosterone and cortisol) were excluded from the analysis. All patients gave written informed consent and were recruited under protocol 00-CH-0160 (clinical trial number NCT00005927) of the Eunice Kennedy Shriver National Institute of Child Health and Human Development, National Institutes of Health. Per protocol, all patients with or without elevated ARR underwent confirmatory testing with SST and oral salt loading as outlined later. The protocol was not designed to include the fludrocortisone or captopril challenge tests for case confirmation. Automated office blood pressure (BP) measurement was performed in all patients throughout their evaluation.

\section{2 | Medical treatment}

As outlined by the Clinical Practice Guidelines of the Endocrine Society on PA, ${ }^{1}$ medications that may lead to false-positive or false-negative ARR results were all discontinued at least 2 weeks prior to the initial biochemical evaluation, and treatment with a mineralocorticoid receptor antagonist, such as spironolactone, was discontinued at least 4 weeks prior to testing. Antihypertensive therapy with minimal effect on ARR was achieved with one or more of the following oral agents: $\alpha$-blocker (doxazosin or terazosin), calcium channel blocker (verapamil), and/or vasodilator (hydralazine). Patients taking mineralocorticoid receptor antagonists, angiotensin-converting enzyme inhibitors, or angiotensin II receptor blockers during the evaluation were excluded from the current analysis. Potassium was normalized in all patients and liberal salt intake prior to biochemical evaluation was encouraged.

\subsection{Biochemical evaluation}

Patients underwent a stepwise diagnostic approach for PA diagnosis, as previously described. ${ }^{1,14}$ PAC (ng/dL) and 24-hour UA ( $\left.\mu \mathrm{g} / 24 \mathrm{~h}\right)$ were measured using liquid chromatography-tandem mass spectrometry (Mayo Medical Laboratories). PRA (ng/mL-h) was calculated by incubating its substrate, angiotensinogen, and measuring the

Etiology for evaluation, entire cohort $(\mathrm{N}=59)$ :

- Adrenal incidentaloma/bilateral adrenal hyperplasia $(n=29)$

- Resistant hypertension ( $\mathrm{n}=11)$

- Hypertension and hypokalemia $(n=19)$

Confirmatory tests for primary aldosteronism $(n=46)$ :

- Oral salt loading, > vs $\leq 12 \mu \mathrm{g} / 24 \mathrm{~h}(23 / 11)$

- Saline suppression test, > vs $\leq 10 \mathrm{ng} / \mathrm{dL}(17 / 25)$

- $\quad \geq 1$ positive confirmatory test $(n=29)$

Etiology for evaluation, ARR $\geq 20(n=28)$ :

- Adrenal incidentaloma/bilateral adrenal hyperplasia $(n=6)$

- Resistant hypertension $(\mathrm{n}=8)$

- Hypertension and hypokalemia $(n=14)$

Confirmatory tests for primary aldosteronism $(n=26)$ :

- Oral salt loading, > vs $\leq 12 \mu \mathrm{g} / 24 \mathrm{~h}(17 / 2)$

- Saline suppression test, $>$ vs $\leq 10 \mathrm{ng} / \mathrm{dL}(15 / 10)$

- $\quad \geq 1$ positive confirmatory test $(n=22)$
Etiology for evaluation, ARR $<20(n=31)$ :

- Adrenal incidentaloma/bilateral adrenal hyperplasia $(n=23)$

- Resistant hypertension ( $n=3)$

- Hypertension and hypokalemia $(n=5)$

Confirmatory tests for primary aldosteronism $(n=20)$ :

- Oral salt loading, > vs $\leq 12 \mu \mathrm{g} / 24 \mathrm{~h}(6 / 9)$

- Saline suppression test, > vs $\leq 10 \mathrm{ng} / \mathrm{dL}(2 / 15)$

- $\quad \geq 1$ positive confirmatory test $(n=7)$

FIGURE 1 Flowchart of the distribution of our cohort per etiology and confirmatory tests for primary aldosteronism. ARR indicates aldosterone to renin ratio. Resistant hypertension is defined as blood pressure above goal in spite of full doses of at least 3 antihypertensive medications, including a diuretic 
product angiotensin I by tandem mass spectrometry (Mayo Medical Laboratories). ARR was reported in conventional units (ng/dL per ng/ $\mathrm{mL} \cdot \mathrm{h}$ ), with an adopted cutoff value of $\geq 20$ for a positive case detection for PA. ${ }^{1}$ All patients underwent SST and oral salt-loading tests and 24-hour UA for confirmation of PA. ${ }^{1}$ SST was performed in the morning with a continuous infusion of $2 \mathrm{~L}$ of $0.9 \%$ normal saline over 4 hours and PAC measured at baseline and hourly. Postinfusion PACs (suppressed PAC, sPAC) $>10 \mathrm{ng} / \mathrm{dL}$ were considered confirmatory for PA. During the oral salt-loading test, patients were given $2 \mathrm{~g}$ of sodium tablets three times daily for 3 days and urinary sodium and aldosterone were measured in a 24-hour urine collection from the morning of day 3 until the morning of day 4 . UA (suppressed UA) $>12 \mu \mathrm{g} / 24 \mathrm{~h}$ along with a urine sodium $>200 \mathrm{nmol} / 24 \mathrm{~h}$ confirmed the diagnosis of PA.

\section{4 | Statistical analysis}

Statistical calculations were performed with SPSS 20.0 software (SPSS Inc). Results are expressed as mean \pm standard deviation unless otherwise indicated. BMI and suppressed UA were normally distributed, whereas PAC, PRA, ARR, and SPAC were all logarithmically transformed to induce approximate normality. For group comparisons, the independent Student $t$ test or one-way analysis of variance were used to analyze differences in numerical variables, and the chi-square test was employed to analyze differences in categorical variables. The Pearson product was used for analysis of correlations between variables. Since the associations between BMI and PAC and other variables showed a U-shaped correlation and not a linear relationship, we performed a statistical analysis for quadratic correlation; the $F$ test was conducted to estimate the superiority of quadratic correlation over linear correlation. The $r$ correlation coefficient changes between the linear and quadratic correlations and the $P$ values for these changes are presented. The $P$ value for significance was set at $<.05$.

\section{3 | RESULTS}

\section{1 | Descriptive characteristics}

The current analysis included 59 patients, with a mean age of $49.3 \pm 16.0$ years and mean BMI of $32.6 \pm 6.8 \mathrm{~kg} / \mathrm{m}^{2}$; 39 (66.1\%) were women. The patients were divided into five subgroups according to their BMI, selected based on BMI cutoff values used by the Endocrine Society Guidelines for pharmaceutical management of obesity ${ }^{15}$ (characteristics detailed in Table 1): 18 to $24.9 \mathrm{~kg} / \mathrm{m}^{2}$ ( $\left.\mathrm{n}=7\right), 25$ to $29.9 \mathrm{~kg} / \mathrm{m}^{2}$ ( $\left.\mathrm{n}=12\right), 30$ to $34.9 \mathrm{~kg} / \mathrm{m}^{2}$ ( $\left.\mathrm{n}=22\right), 35$ to $39.9 \mathrm{~kg} / \mathrm{m}^{2}(\mathrm{n}=9)$, and $\geq 40 \mathrm{~kg} / \mathrm{m}^{2}(\mathrm{n}=9)$. Seventeen patients had a negative confirmatory test for PA (Figure 1).

Both systolic BP (SBP) and diastolic BP (DBP) measurements were comparable between the different BMI categories (Table 1). SBP negatively correlated with Log-PRA $(r=-.3, P=.009)$ and positively correlated with Log-ARR ( $r=.3, P=.01)$ but not with Log-PAC. However, both SBP $(r=.3, P=.02, n=42)$ and DBP $(r=.3, P=.03, n=42)$ correlated positively with Log-sPAC. Among patients with elevated BP (>140/90 mm Hg),
BMI showed a significant quadratic correlation with PAC $(r=.5, P=.03$; $P$ for $r$ change .04).

\subsection{Association between $\mathrm{BMI}$ and test results}

\subsection{1 | Full study population}

BMI correlated negatively with Log-PAC and BMI $<40 \mathrm{~kg} / \mathrm{m}^{2}(\mathrm{n}=50$, $r=-.4 ; P=.02$ ), with a borderline positive correlation with $B M I \geq 40 \mathrm{~kg} /$ $\mathrm{m}^{2}(\mathrm{n}=9, \mathrm{r}=.6 ; P=.065)$. BMI showed a significant $\mathrm{U}$-shaped correlation in the full cohort ( $r=.45, P=.02$; Figure $2 A)$, increasing the $r$ by $.12(P=.02$ for change) compared with the linear model. Moreover, BMI showed a significant quadratic correlation with suppressed PAC and a similar trend with suppressed UA levels (Figure $3 \mathrm{~A}$ and $3 \mathrm{~B}$, respectively), with $r$ increasing by .25 ( $P$ for $r$ change .05 ) and .11 ( $P$ for $r$ change .07 ) compared with the linear models, respectively. The analysis results did not change after controlling for plasma potassium levels and when including only women. The quadratic correlation between $\mathrm{BMI}$ to random PAC $(P=.004)$ and to PAC after SST $(P=.004)$ remained statistically significant after adjusting for age. No difference was found in $B P$ between obese and nonobese patients ( $P=.5$ for SBP and $P=.2$ for DBP).

\subsection{2 | Subgroup analysis according to ARR}

Among patients with PA confirmed by SST or oral salt loading, patients with $\mathrm{BMI}<35 \mathrm{~kg} / \mathrm{m}^{2}$ had a trend for higher SBP (>140 mm Hg, 66.7\% vs $25 \% ; P=.06$ ), and for higher DBP (>90 mm $\mathrm{Hg}, 38.1 \%$ vs $12.5 \%$; $P=.2)$. Patients with ARR $\geq 20(n=28,47.5 \%)$ had higher SBP $(142 \pm 16$ vs $131 \pm 18 \mathrm{~mm} \mathrm{Hg}, P=.02)$ when compared with patients with a lower ARR. Mean DBP was comparable $(82 \pm 13$ vs $77 \pm 11 \mathrm{~mm} \mathrm{Hg}$, not significant), as was mean BMI $\left(31.1 \pm 5.8\right.$ vs $33.9 \pm 7.4 \mathrm{~kg} / \mathrm{m}^{2}$, not significant). The correlation coefficient for BMI and Log-PAC ( $r=.6, P=.001)$ was higher using a quadratic compared with a linear model $(P$ for $r$ change<.001), which was also seen with $\mathrm{BMI}$ and Log-PRA ( $r=.6, P=.01$; $P$ for $r$ change .02). Similarly, sPAC levels had a stronger correlation with BMI using a quadratic model ( $r=.7, P=.002$; $P$ for $r$ change .07 ). Moreover, among patients with lower $A R R<20$, the quadratic model showed a better correlation between BMI and both Log-PAC ( $r$ change $.4, P$ for $r$ change $<.001$ ) and Log-PRA ( $r$ change .2, $P$ for $r$ change .02 ).

\subsection{3 | Subgroup analysis according to confirmatory testing}

Twenty-nine patients (29 of $46,63.0 \%$ ) had a confirmed diagnosis of PA either by SST (17 of 42 ) or oral sodium loading (23 of 34 ), including 8 patients with positive results on both tests. Among all patients with confirmed $\mathrm{PA}, \mathrm{BMI}$ had a strong quadratic correlation with LogPAC ( $r=.6, P=.004$; Figure 2B), increasing the $r$ for the correlation by .2 compared with the linear correlation analysis ( $P$ for change .008). Moreover, BMI had a quadratic correlation with $\operatorname{SPAC}(r=.6, P=.05)$, increasing the $r$ coefficient by .1 compared with the linear model $(P$ for change .06). BMI and Log-PRA did not correlate, probably because of the high rate of undetectable PRA values (23 of $29,79 \%$ ). 
TABLE 1 Study population characteristics according to BMI categories

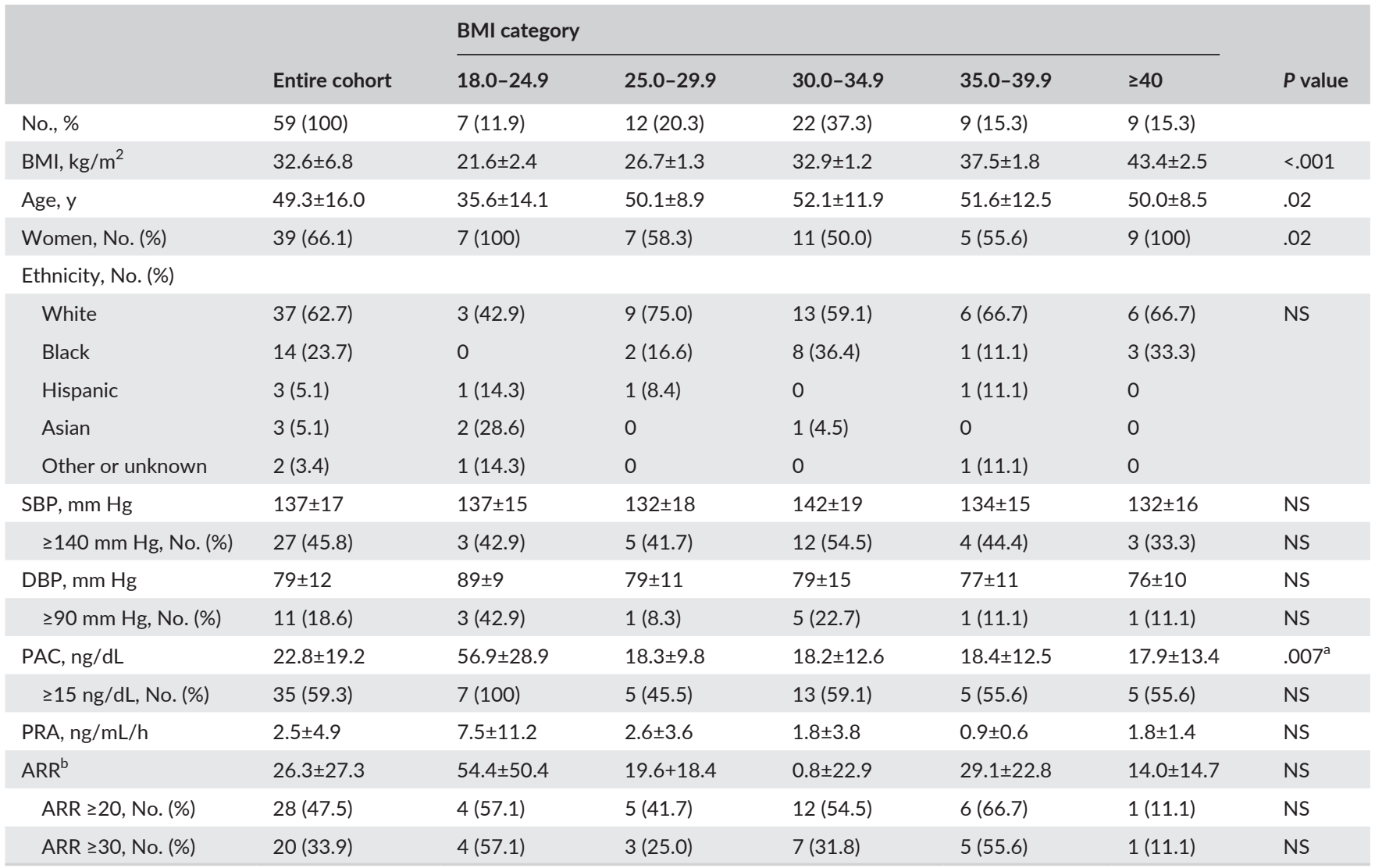

${ }^{a}$ Kruskal-Wallis test.

${ }^{b}$ Aldosterone to renin ratio (ARR) in conventional units (ng/dL per $\mathrm{ng} / \mathrm{mL} \cdot \mathrm{h}$ ).

Abbreviations: BMI, body mass index; DBP, diastolic blood pressure; NS, not significant; PAC, plasma aldosterone concentration; PRA, plasma renin activity; SBP, systolic blood pressure.
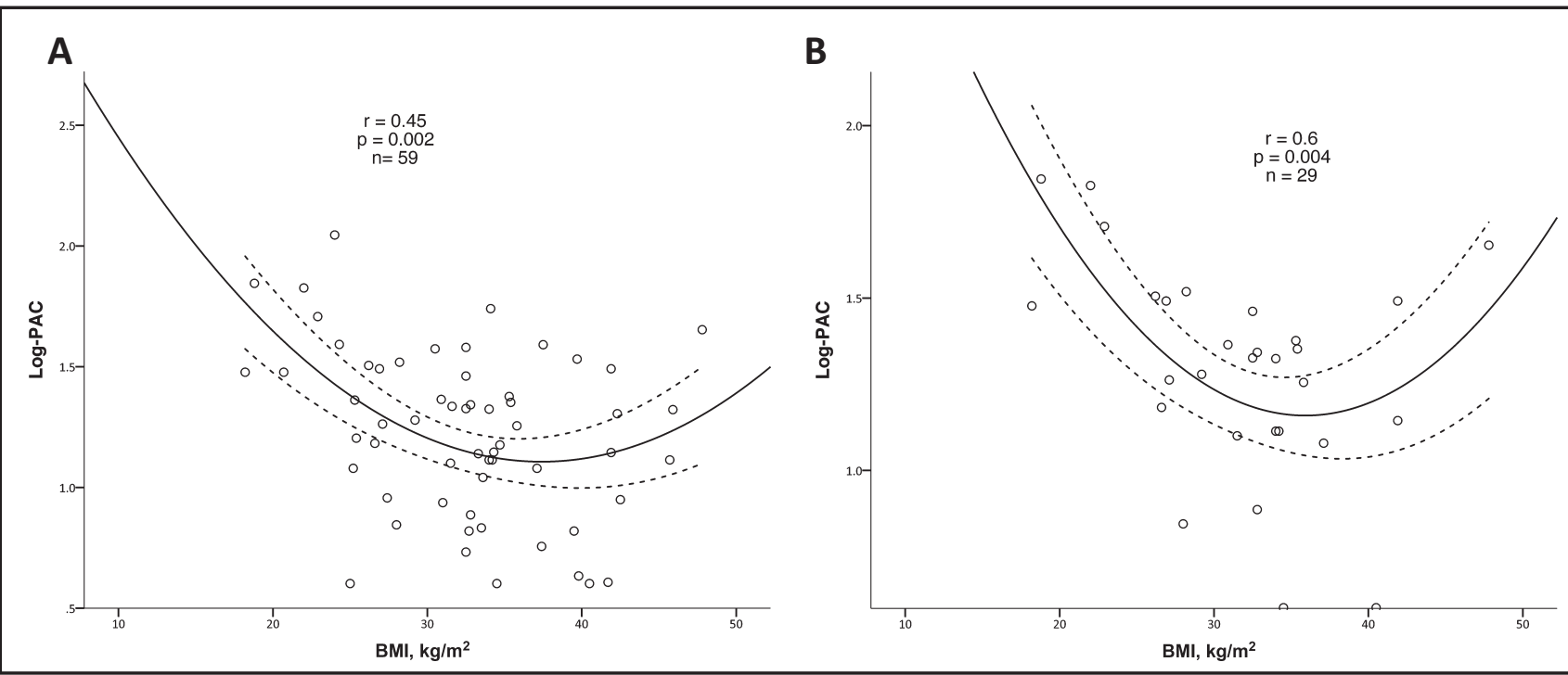

FIGURE 2 Correlation analysis between body mass index (BMI) and plasma aldosterone concentration (PAC; Log10) in the study population (A), and in patients with confirmed primary aldosteronism (PA) (B). PA was diagnosed according to PAC >10 ng/dL following administration of $2 \mathrm{~L}$ of sodium chloride $0.9 \%$ over 4 hours, or according to urinary aldosterone (UA) collection $>12 \mu \mathrm{g} / 24 \mathrm{~h}$ following oral sodium loading in the presence of urinary sodium $>200 \mathrm{nmol} / 24 \mathrm{~h}$ 

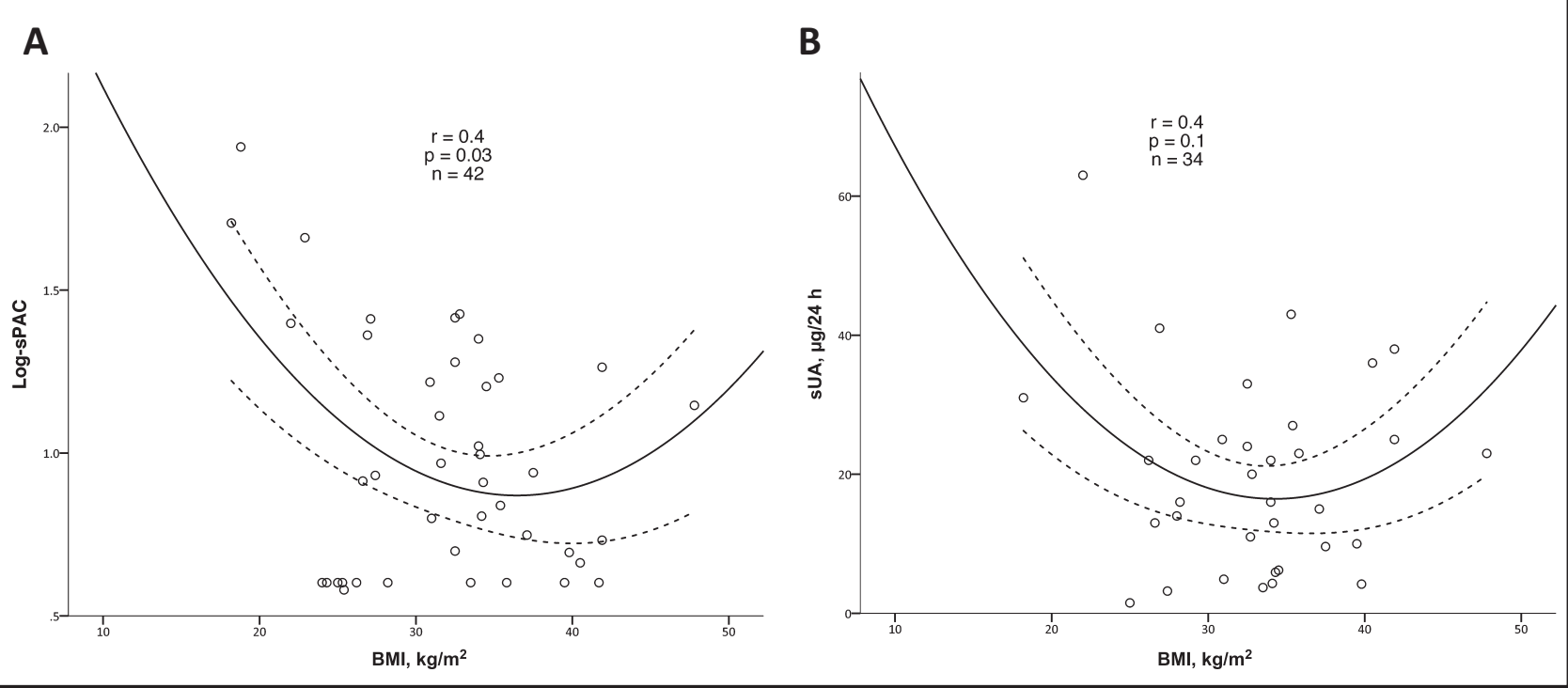

FIGURE 3 Correlation analysis of body mass index (BMI) with plasma aldosterone concentration (PAC) following saline suppression tests (sPAC) (A) and urinary aldosterone (UA) collection following oral sodium loading (sUA) (B). Primary aldosteronism was diagnosed according to $\mathrm{PAC}>10 \mathrm{ng} / \mathrm{dL}$ following administration of $2 \mathrm{~L}$ of sodium chloride $0.9 \%$ over 4 hours, or according to UA collection $>12 \mu \mathrm{g} / 24 \mathrm{~h}$ following oral sodium loading in the presence of urinary sodium $>200 \mathrm{nmol} / 24 \mathrm{~h}$

\subsection{Impact of different BMIs on ARR accuracy}

The receiver operating characteristic curve for the full study population $(n=46$, area under the receiver operating characteristic curve=0.798; Figure 4A) and for patients with $\mathrm{BMI}<30 \mathrm{~kg} / \mathrm{m}^{2}(\mathrm{n}=18)$ and $\geq 30 \mathrm{~kg} / \mathrm{m}^{2}(\mathrm{n}=27)$ revealed excellent accuracy of ARR for case detection of PA among patients with $\mathrm{BMI}<30 \mathrm{~kg} / \mathrm{m}^{2}$ (area under the receiver operating characteristic curve $=0.970$, Figure $4 \mathrm{~B}$ ), compared with a lower accuracy among patients with obesity (area under the receiver operating characteristic curve $=0.621$, Figure $4 C$ ). The diagnosis of PA was defined as PAC $\geq 10 \mathrm{ng} / \mathrm{dL}$ following SST. However, similar patterns were found using lower PAC cutoff values: ARR accuracy for PA diagnosis in patients with BMI $\geq 30 \mathrm{~kg} / \mathrm{m}^{2},<30 \mathrm{~kg} / \mathrm{m}^{2}$, or both were $0.959,1.0$, and 0.922 for $P A C \geq 5 \mathrm{ng} / \mathrm{dL}$, and 0.906, 1.0, and 0.844 for $P A C \geq 7 \mathrm{ng} / \mathrm{dL}$, respectively.

The positive predictive value (PPV) for $A R R \geq 20$ and $A R R \geq 30$ among patients with $\mathrm{BMI}<30 \mathrm{~kg} / \mathrm{m}^{2}$ was $100 \%$, whereas the parallel values among patients with obesity were $76.5 \%$ and $63.6 \%$, respectively. Similarly, the calculated NPV of low ARR were lower among patients with higher vs lower BMI groups (Table 2).

\section{4 | DISCUSSION}

Our analysis evaluated for the first time the accuracy of case detection of PA among patients with a wide range of BMI values. We showed complex associations between $\mathrm{BMI}$ and $\mathrm{PAC}$, with a negative correlation for BMI $<40 \mathrm{~kg} / \mathrm{m}^{2}$ and a higher accuracy of quadratic correlation between $\mathrm{BMI}$ and $\mathrm{PAC}$, when compared with linear models. This association was also found among patients with elevated $(\geq 20)$ and nonelevated ARR, hypertension (>140/90 mm Hg), and confirmed
PA. Importantly, high ARR yielded lower PPV and NPV for PA diagnosis among patients with obesity (BMI $\left.\geq 30 \mathrm{~kg} / \mathrm{m}^{2}\right)$, with lower accuracy, when compared with the lower BMI cohort. Clinically, this translates to excellent PPV (100\%) for ARR among patients with low $\mathrm{BMI}$ and lower NPV of ARR among patients with obesity, which may weaken the utility of ARR for case detection of PA in patients with a $\mathrm{BMI} \geq 30 \mathrm{~kg} / \mathrm{m}^{2}$ when SST or oral salt loading is used for confirmation. In addition, we showed that the highest accuracy for case detection of PA was achieved using an aldosterone cutoff level of $5 \mathrm{ng} / \mathrm{dL}$ or $7 \mathrm{ng} /$ $\mathrm{dL}$, when compared with $10 \mathrm{ng} / \mathrm{dL}$ during SST, for all BMI categories.

Studies examining the effects of BMI values on PAC have yielded inconsistent results. ${ }^{6}$ Goodfriend and colleagues ${ }^{10}$ reported on the positive correlation between BMI and PAC among women and both sexes. Bentley-Lewis and coworkers ${ }^{11}$ described higher UA levels but no difference in PAC among patients with vs patients without obesity. Two studies showed that higher PACs were observed among patients with severe obesity $\left(\left[\mathrm{BMI}>35 \mathrm{~kg} / \mathrm{m}^{2}\right]^{12}\right.$ and [mean BMI $\left.\left.47.8 \mathrm{~kg} / \mathrm{m}^{2}\right]^{16}\right)$, although a study by O'Seaghdha and colleagues ${ }^{17} \mathrm{did}$ not find associations between BMI and PAC, PRA, or ARR in a large cohort. A recent study by Joseph and colleagues ${ }^{13}$ divided patients into PAC quintiles and showed a higher mean BMI in the lower compared with the second quintiles, in line with our results. A thorough review of the literature ${ }^{6}$ suggested that a nonlinear relationship between BMI and PAC might explain this inconsistency, which is in keeping with our current analysis and supporting a quadratic rather than linear correlation between BMI and PAC, PRA, or ARR.

Several basic and clinical studies on various populations, including patients with PA, have described the complex relationship between obesity and the renin-angiotensin system. These observations may in part explain the quadratic association observed between BMI and PRA or PAC. Renin secretion among individuals with obesity is increased by 

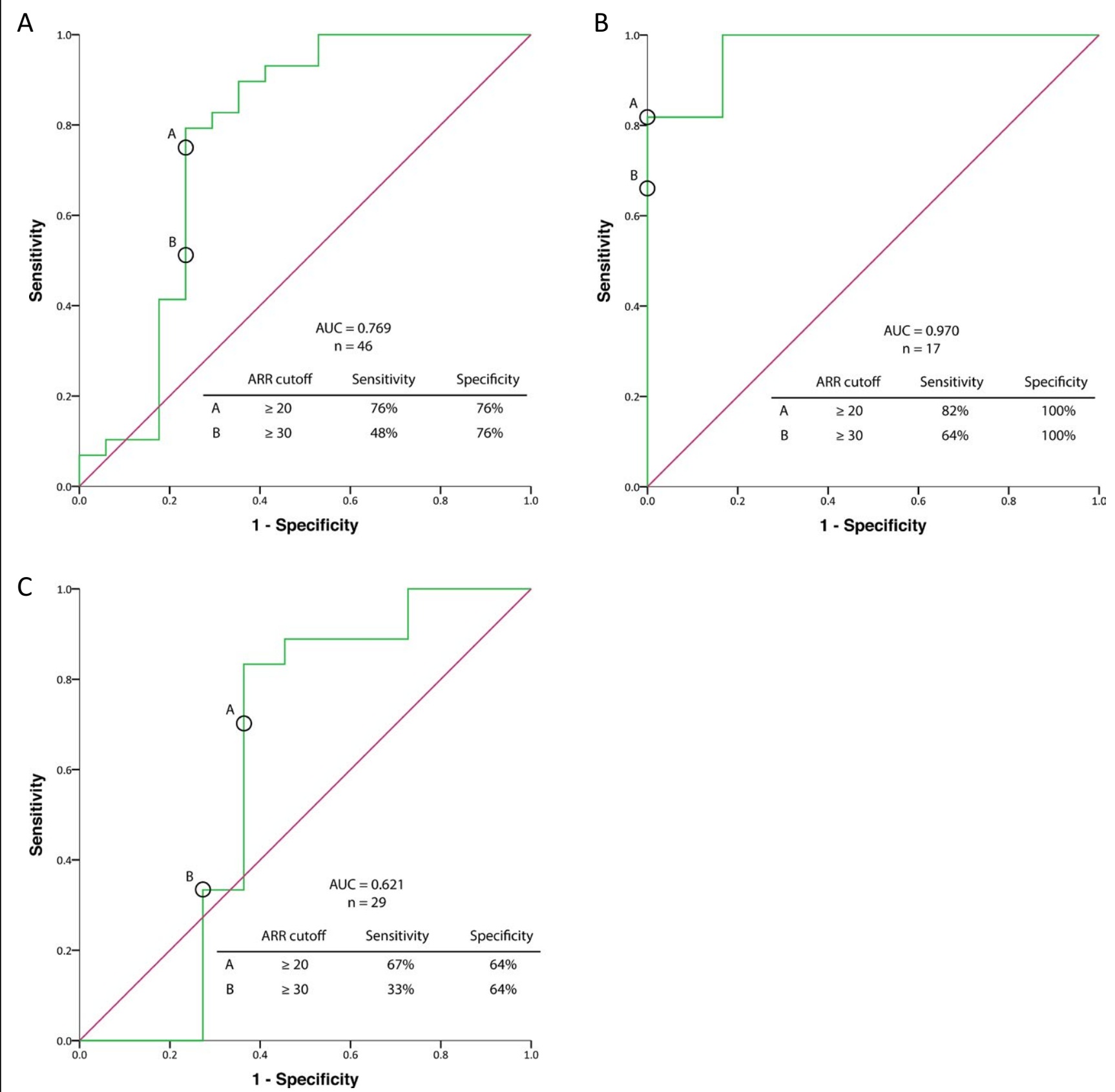

FIGURE 4 Evaluation of the accuracy of aldosterone to renin ratio (ARR) for the diagnosis of primary aldosteronism (PA) using receiver operating curve analysis in the full study cohort (A), in patients with body mass index $(B M I)<30 \mathrm{~kg} / \mathrm{m}^{2}(B)$, and in patients with $\mathrm{BMI} \geq 30 \mathrm{~kg} /$ $\mathrm{m}^{2}$ (C). PA was diagnosed according to plasma aldosterone concentration $>10 \mathrm{ng} / \mathrm{dL}$ following administration of $2 \mathrm{~L}$ of sodium chloride $0.9 \%$ over 4 hours, or according to urinary aldosterone collection $>12 \mu \mathrm{g} / 24 \mathrm{~h}$ following oral sodium loading in the presence of urinary sodium $>200 \mathrm{nmol} / 24 \mathrm{~h}$. AUC indicates area under the receiver operating characteristic curve

sympathetic nerve activity $^{18}$ and peroxisome proliferator-activated receptor $\gamma$ stimulation ${ }^{19}$ and decreased by estrogen therapy ${ }^{20}$ through estrogen receptor- $\beta$ stimulation. ${ }^{21}$ Aldosterone can be directly stimulated by adipokines (eg, CTRP-1), which are secreted from adipose tissues by sensitizing normal adrenal and adenoma cells to angiotensin $\mathrm{II}^{22-24}$ suggesting a role for adipose tissue in regulating aldosterone secretion. Adipocytes have direct renin-like activity and are capable of converting angiotensin to angiotensin I and angiotensin II. ${ }^{25}$ It is unclear whether angiotensin I and angiotensin II lead to increased aldosterone production in patients with PA, since the process is rather autonomous. Moreover, it is unclear whether excess estrogen levels, which is observed in patients with obesity, might account for a lower PAC through either increased liver metabolism or decreased adrenal secretion (and hence a lower ARR, leading to false-negative screening). Thus, the mechanism underlying the quadratic association observed between $\mathrm{BMI}$ and PRA or PAC in our study requires further research, 
TAB LE 2 Positive and negative predictive values of ARR cutoffs for the diagnosis of $\mathrm{PA}^{\mathrm{a}}$ in the full cohort, with $\left(\mathrm{BMI} \geq 30 \mathrm{~kg} / \mathrm{m}^{2}\right)$ and without $\left(\mathrm{BMI}<30 \mathrm{~kg} / \mathrm{m}^{2}\right)$ obesity

\begin{tabular}{|c|c|c|c|c|}
\hline \multirow[b]{2}{*}{ ARR cutoff } & \multicolumn{2}{|c|}{$\geq 20$ or $<20$} & \multicolumn{2}{|c|}{$\geq 30$ or $<30$} \\
\hline & PPV, \% & NPV, \% & PPV, \% & NPV, $\%$ \\
\hline $\begin{array}{l}\text { All patients }{ }^{\mathrm{b}} \\
(\mathrm{N}=46)\end{array}$ & 84.6 & 65.0 & 77.8 & 46.4 \\
\hline $\mathrm{BMI} \geq 30(n=29)$ & 76.5 & 58.3 & 63.6 & 38.9 \\
\hline $\mathrm{BMI}<30(\mathrm{n}=17)$ & 100 & 75.0 & 100 & 60.0 \\
\hline
\end{tabular}

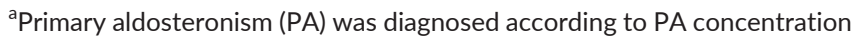
$>10 \mathrm{ng} / \mathrm{dL}$ following administration of $2 \mathrm{~L}$ of sodium chloride $0.9 \%$ over 4 hours, or according to urinary aldosterone collection $>12 \mu \mathrm{g} / 24 \mathrm{~h}$ following oral sodium loading in the presence of urinary sodium $>200 \mathrm{nmol} / 24 \mathrm{~h}$. ${ }^{b}$ Only patients who underwent case validation tests.

Abbreviations: ARR, aldosterone to renin ratio; $\mathrm{BMI}$, body mass index; NPV, negative predictive value; PPV, positive predictive value.

and the role of estrogens in aldosterone secretion and metabolism should be clarified.

Our analysis showed that BMI is an important factor in the case detection and confirmation of PA. Our findings of higher PPV and NPV among patients with lower BMI (Table 2 and Figure 4) are reassuring. However, accuracy of testing for PA seems inferior in obese patients undergoing evaluation for PA. The comparison of ARR accuracy and predictability between different studies is limited as a result of differences in inclusion criteria, sampling conditions (supine or upright), and ARR cutoff values. This is reflected by the wide range of PPV (34\%$75 \%),{ }^{26,27}$ NPV $(84.8 \%-88.0 \%),{ }^{26,27}$ and area under the receiver operating characteristic curve $(0.80-0.97)^{26,28-30}$ reported to date. Only a few studies have performed confirmatory testing for negatively screened patients. ${ }^{31}$ Although the diagnosis of PA in obese patients could be problematic, there are no alternative biochemical strategies for case detection at present. However, although the commonly employed ARR is $\geq 30,{ }^{1}$ our study suggests that with obesity, a threshold of $\geq 20$ could be used for a higher PPV yield (76.5\% vs 63.6\%). Our data also suggest that among patients with $\mathrm{BMI}<30 \mathrm{~kg} / \mathrm{m}^{2}$, a high ARR possibly obviates the need for confirmatory testing, whereas among obese patients, ARR is less accurate. Thus, we recommend a high index of suspicion for PA in this population. In order to have more accurate practical recommendations for the confirmation of PA, future studies with larger sample sizes and using a variety of confirmatory tests are required. In addition, ascertainment of normal reference values for PAC and PRA per BMI category in normal individuals, patients with hypertension, and patients with PA is required, which might increase the reliability of ARR in the case detection of PA, particularly in patients with obesity.

\section{5 | STUDY LIMITATIONS}

Despite the strengths of the current analysis in its research plan and data analysis, several drawbacks exist. First, the sample size was small and may not be generalizable to all forms of PA and a selection bias could not be ruled out given the nature of our referral center. Second, both the lowest and highest BMI strata consisted mostly of women, although the results showed similar correlation patterns. Third, there are limitations of a prespecified ARR of 20 or 30 for case detection of PA. Moreover, the results of the SST and oral sodium suppression examinations as confirmatory tests for PA are not definitive for the diagnosis of PA and have their limitations. ${ }^{32}$ However, our study was designed and approved for these confirmatory tests only. Thus, validating our results using the various confirmatory tests as surrogates for the diagnosis of PA is required. Fourth, measurements of angiotensin I, angiotensin II, estrogens, and variables for calculation of insulin resistance were not available for comparison between the groups, which would have enabled further analysis. Fifth, within-subject variability in PAC measures, which is not uncommon in PA, could have affected the single-measure correlation validity of our analysis. Finally, although we did not find a relationship between BP and BMI, this might be explained by the fact that the patients were medically treated before being included in the study.

\section{6 | CONCLUSIONS}

Our study shows that BMI has a nonlinear correlation with PAC, PRA, and ARR, as well as with confirmatory tests results. This pattern was found among patients with a positive case detection test (ARR $\geq 20$ ) and confirmed PA. The PPV, NPV, and test accuracy of ARR were higher among patients with $B M I<30 \mathrm{~kg} / \mathrm{m}^{2}$ when compared with obese patients, which may affect the diagnosis of PA in this BMI group. Further studies are required to confirm this important association.

\section{CONFLICT OF INTEREST}

The authors have nothing to disclose.

\section{REFERENCES}

1. Funder JW, Carey RM, Mantero F, et al. The management of primary aldosteronism: case detection, diagnosis, and treatment: an endocrine society clinical practice guideline. J Clin Endocrinol Metab. 2016;101:1889-1916.

2. Rossi GP, Bernini G, Caliumi C, et al. A prospective study of the prevalence of primary aldosteronism in 1,125 hypertensive patients. J Am Coll Cardiol. 2006;48:2293-2300.

3. Milliez P, Girerd X, Plouin PF, Blacher J, Safar ME, Mourad JJ. Evidence for an increased rate of cardiovascular events in patients with primary aldosteronism. J Am Coll Cardiol. 2005;45:1243-1248.

4. Funder JW. Primary aldosteronism as a public health issue. Lancet Diabetes Endocrinol. 2016;4:972-973.

5. Ogden CL, Carroll MD, Kit BK, Flegal KM. Prevalence of childhood and adult obesity in the United States, 2011-2012. JAMA. 2014;311:806-814.

6. Byrd JB, Brook RD. A critical review of the evidence supporting aldosterone in the etiology and its blockade in the treatment of obesityassociated hypertension. J Hum Hypertens. Nature Publishing Group. 2014;28:3-9.

7. Fallo F, Pilon C, Urbanet R. Primary aldosteronism and metabolic syndrome. Horm Metab Res. 2012;44:208-214. 
8. Goodfriend TL, Kelley DE, Goodpaster BH, Winters SJ. Visceral obesity and insulin resistance are associated with plasma aldosterone levels in women. Obes Res. 1999;7:355-362.

9. Lamounier-Zepter V, Rotthoff T, Ansurudeen I, et al. Increased aldosterone/renin quotient in obese hypertensive women: a novel role for low-density lipoproteins? Horm Metab Res. 2006;38:471-475.

10. Goodfriend TL, Egan BM, Kelley DE. Aldosterone in obesity. Endocr Res. 1998;24:789-796.

11. Bentley-Lewis R, Adler GK, Perlstein T, et al. Body mass index predicts aldosterone production in normotensive adults on a high-salt diet. $J$ Clin Endocrinol Metab. 2007;92:4472-4475.

12. Sarzani R, Guerra F, Mancinelli L, Buglioni A, Franchi E, Dessì-Fulgheri P. Plasma aldosterone is increased in class 2 and 3 obese essential hypertensive patients despite drug treatment. Am J Hypertens. 2012;25:818-826.

13. Joseph JJ, Echouffo-Tcheugui JB, Kalyani RR, et al. Aldosterone, renin, and diabetes mellitus in African Americans: the Jackson Heart Study. J Clin Endocrinol Metab. 2016;101:1770-1778.

14. Zilbermint M, Xekouki P, Faucz FR, et al. Primary aldosteronism and ARMC5 variants. J Clin Endocrinol Metab. 2015;100:E900-E909.

15. Apovian CM, Aronne LJ, Bessesen DH, et al. Pharmacological management of obesity: an Endocrine Society clinical practice guideline. $J$ Clin Endocrinol Metab. 2015;100:342-362.

16. Andronico G, Cottone S, Mangano MT, et al. Insulin, renin-aldosterone system and blood pressure in obese people. Int J Obes Relat Metab Disord. 2001;25:239-242.

17. O'Seaghdha CM, Hwang SJ, Vasan RS, et al. Correlation of renin angiotensin and aldosterone system activity with subcutaneous and visceral adiposity: the Framingham Heart Study. BMC Endocr Disord. 2012;12:3.

18. Alvarez GE, Beske SD, Ballard TP, Davy KP. Sympathetic neural activation in visceral obesity. Circulation. 2002;106:2533-2536.

19. Todorov VT. PPARgamma-dependent control of renin expression: molecular mechanisms and pathophysiological relevance. PPAR Res. 2013;2013:451016.

20. Schunkert H, Danser AH, Hense HW, Derkx FH, Kürzinger S, Riegger GA. Effects of estrogen replacement therapy on the renin-angiotensin system in postmenopausal women. Circulation. 1997;95:39-45.

21. Caroccia B, Seccia TM, Campos AG, et al. GPER-1 and estrogen receptor- $\beta$ ligands modulate aldosterone synthesis. Endocrinology. 2014;155:4296-4304.

22. Ehrhart-Bornstein M, Lamounier-Zepter V, Schraven A, et al. Human adipocytes secrete mineralocorticoid-releasing factors. Proc Natl Acad Sci USA. 2003;100:14211-14216.
23. Jeon JH, Kim K, Kim JH, et al. A novel adipokine CTRP1 stimulates aldosterone production. FASEB J. 2008;22:1502-1511.

24. Rossi GP, Sticchi D, Giuliani L, et al. Adiponectin receptor expression in the human adrenal cortex and aldosterone-producing adenomas. Int J Mol Med. 2006;17:975-980.

25. Saye JA, Ragsdale NV, Carey RM, Peach MJ. Localization of angiotensin peptide-forming enzymes of 3T3-F442A adipocytes. Am J Physiol. 1993;264:C1570-C1576.

26. Schwartz GL, Chapman AB, Boerwinkle E, Kisabeth RM, Turner ST. Screening for primary aldosteronism: implications of an increased plasma aldosterone/renin ratio. Clin Chem. 2002;48:1919-1923.

27. Jansen PM, van den Born BJ, Frenkel WJ, et al. Test characteristics of the aldosterone-to-renin ratio as a screening test for primary aldosteronism. J Hypertens. 2014;32:115-126.

28. Tiu SC, $\mathrm{Choi} \mathrm{CH}$, Shek CC, et al. The use of aldosterone-renin ratio as a diagnostic test for primary hyperaldosteronism and its test characteristics under different conditions of blood sampling. J Clin Endocrinol Metab. 2005;90:72-78.

29. Ducher M, Mounier-Véhier C, Baguet JP, et al. Aldosterone-to-renin ratio for diagnosing aldosterone-producing adenoma: a multicentre study. Arch Cardiovasc Dis. 2012;105:623-630.

30. Kuo CC, Wu VC, Tsai CW, et al. Combining body mass index and serum potassium to urine potassium clearance ratio is an alternative method to predict primary aldosteronism. Clin Chim Acta. 2011;412:1637-1642.

31. Montori VM, Young WF. Use of plasma aldosterone concentrationto-plasma renin activity ratio as a screening test for primary aldosteronism. A systematic review of the literature. Endocrinol Metab Clin North Am. 2002;31:619-632, xi.

32. Rossi GP, Belfiore A, Bernini G, et al. Prospective evaluation of the saline infusion test for excluding primary aldosteronism due to aldosterone-producing adenoma. J Hypertens. 2007;25:1433-1442.

How to cite this article: Tirosh A, Hannah-Shmouni F, Lyssikatos C, et al. Obesity and the diagnostic accuracy for primary aldosteronism. J Clin Hypertens. 2017;19:790-797. https://doi.org/10.1111/jch.13041 